\title{
Antioxidant and skin protection effect of morin upon UVA exposure
}

Hee Jung Yong ${ }^{1}$ and Jin Jung Ahn ${ }^{2^{*}}$

\begin{abstract}
Background: Morin is a family of phenolic compounds and is a bioflavonoid ingredient in fruits and vegetables. Morin exhibits various biological activities, including antioxidant cell protection and antimutagenic and anti-inflammatory effects; these activities safely minimize free radical-mediated damage biologically. However, the photoaging mitigation effect of morin on skin cells remains unknown. To investigate the effect of the morin on cell senescence mitigated against photoaging, cell viability, antioxidation, and anti-inflammation experiments were conducted. As a natural result of oxygen consumption, reactive oxygen species (ROS) in the form of harmful superoxides and hydroxyl radicals are generated through an oxidation reaction involving heavy metal cations such as iron. This adversely affects DNA, lipids, and proteins; therefore, organisms have a self-protective mechanism against oxidative stress via enzymes such as catalase (CAT) and superoxide dismutase (SOD), molecules such as glutathione, and proteins such as thioredoxin. Therefore, in this study, the antioxidative and skin protection functions of morin were examined to investigate the possibility of cosmetics.
\end{abstract}

Methods: To examine morin-mediated anti-photoaging mechanisms, human dermal fibroblasts (HDFs) were selected as the model cell line and UVA was selected as the stimulus source. The water-soluble tetrazolium salt-1 assay was performed to assess cell viability and cytoxicity in UV-exposed HDFs. To examine the molecular mechanism underlying the antioxidation capacity of morin, genes were analyzed using qRT-PCR, the expressions of several antioxidant enzymes were monitored, and the effect of morin on GPx1, CAT, HO-1, and NRF2 expressions in UV-exposed HDFs was assessed.

Results: The results of the morin toxicity showed the cell viability was above 100\% when the concentration of morin was set at 20 and $50 \mu \mathrm{M}$. The cytotoxicity test for oxidative stress through UVA showed that the appropriate intensity of UVA $10 \mathrm{~J} / \mathrm{cm}^{2}$ was set as the cell viability reduced by $10 \mathrm{~J} / \mathrm{cm}^{2}$. And the cell survival over $100 \%$ rate after the morin treatment was 20 and $50 \mu \mathrm{M}$ cell. A result of mRNA experiments verified that the expression of the antioxidant enzyme genes GPX1, CAT, HO-1, and NRF2 increased with morin, in a concentration-dependent manner.

Conclusion: Morin increases the expression of antioxidant enzymes, which facilitates the antioxidant mechanism to respond to oxidative stress associated with exposure to UV and heat, which are considered to be the most harmful factors damaging the skin cells. This results in ROS removal, a byproduct of the natural metabolism of oxygen and the protection of neurons and proteins from toxicity. In conclusion, this study verified the applicability of morin as a cosmetic ingredient for the protection of cells against oxidization and UV.

Keywords: Morin, Fibroblast, UVA, Antioxidant, Cytoprotective effect

\footnotetext{
* Correspondence: 1THEgirl@swc.ac.kr

This work is part of Jin Jung Ahn's Ph.D. thesis at KonKuk University, Seoul,

South Korea.

2Department of Cosmetology, Suwon Women's University, Suwon-si,

Kyonggi-do, South Korea

Full list of author information is available at the end of the article
} 


\section{Background}

As a natural result of oxygen consumption, reactive oxygen species (ROS) in the form of harmful superoxides and hydroxyl radicals are generated through an oxidation reaction involving heavy metal cations such as iron. This adversely affects DNA, lipids, and proteins; therefore, organisms have a self-protective mechanism against oxidative stress, involving enzymes such as catalase (CAT) and superoxide dismutase (SOD), molecules such as glutathione, and proteins such as thioredoxin and glutaredoxin (Cabiscol et al. 2000). ROS created during cellular metabolic processes are by-products of reactions involving oxidase and oxygen lyase. The oxidation state of cells is a major factor that alters gene expression and activity. In particular, imbalanced $\mathrm{O}_{2}$ generates $\mathrm{H}_{2} \mathrm{O}_{2}$, which is not precisely defined as a radical but its transformation facilitates quick reaction; SOD contains transition metals $\left(\mathrm{Cu}^{2+}\right.$ and $\left.\mathrm{Mn}^{3+}\right)$ to enable rapid electron exchange. The most abundant peroxidase is glutathione peroxidase (GSH$\mathrm{Px}$ ), which is present throughout the cytoplasm and mitochondria. This enzyme contains selenium, a transition metal, at its active site and uses reduced glutathione (GSH) as a substrate to move electrons to $\mathrm{H}_{2} \mathrm{O}_{2}$ and other peroxides to generate water.

CAT mainly uses iron ions at the active site with peroxisomes to decompose $\mathrm{H}_{2} \mathrm{O}_{2}$ into water and $\mathrm{O}_{2}$ (Matés 2000). Therefore, an antioxidant mechanism is activated when insufficient removal of ROS has occurred, and it plays an important role in cytoprotection as a natural biological defense mechanism that protects proteins from oxidative stress. Because molecules that are sensitive to various oxidoreduction reactions participate in numerous cellular reactions such as cell proliferation, cell growth, cell cycle arrest, and cell death, antioxidants and antioxidant enzymes determine the oxidoreduction potential of cells and react with thiol groups to adjust various biological antioxidative activities (Mates et al. 2012). Continuous exposure to UVA causes ROS and DNA oxidization and generates a precursor of melanin that results in pigmentation and erythema. In addition, such exposure depletes cellular antioxidants and generates hydrogen peroxide, superoxide anion, singlet oxygen, hydroxyl radicals, and nitric oxide (NO), which cause free radical-induced inflammatory responses (Ichihashi et al. 2009). ROS may induce immune reactions against infection, but when present in excess levels, it may induce lipid peroxidation and damage proteins and nucleic acids (Castro and Freeman 2001). Therefore, the existence of an antioxidative mechanism is very important for cellular homeostasis.

The antioxidative functions of cells are adjusted by antioxidant enzymes and antioxidants. Antioxidants include glutathione (GSH), thioredoxin (Trx), and melatonin. Antioxidant enzymes include superoxide dismutase (SOD), glutathione peroxidase (GPx), glutathione reductase (GR), catalase (CAT), and heme oxygenase (HO) (Castro and Freeman 2001; Bhattacharya et al. 2015). Among the major antioxidant mechanisms, Keap1-NRF2 is a major modulator of cytoprotective reactions against oxidation and stress and one of the core signaling proteins; it is a combination of NRF2 and Keap1, transcription factors that combine with antioxidant response element (ARE) along with small Maf protein. Protein 1, which is a repressor protein, promotes protein decomposition via the ubiquitin-proteasome pathway. Keap1 is a protein rich in cysteine, but the details of the mechanism by which it induces NRF2 activity remain unknown. However, it is known that cysteine deformation at the thiol of Keap1 induces the degradation of NRF2 (Kansanen et al. 2013). NRF2 removes carcinogens, ROS, and other DNA-damaging substances as a major modulator involved in cytoprotection. It also inhibits tumors and cancer metastasis. The antioxidant system of Keap1-NRF2 protects proteins and DNA against oxidant damage by ROS by adjusting the important transporters for cell detoxification. As a result, the Keap1-NRF2 system is an important target for treating cancer and neurodegenerative diseases, autoimmune diseases, and inflammatory diseases. The prevention of Keap1 activity and NRF2 induction is effective to promote antioxidant reactions in the battle against disease (Canning et al. 2015).

UVA penetrates indoors even on cloudy days and invades down to the dermal layer of the skin. It is considered a primary cause of skin aging and induces reactions in the immune system. The dermis comprises 80 or $90 \%$ of the skin and consists of collagen (70\%), elastin, and extracellular matrix originating from the fibroblasts, along with the blood vessels and neurons. The dermis contributes to the skin thickness, and is involved in wrinkle formation, and intervenes in the metabolism, wound healing, and cell repair. Langerhans cells, mast cells, and white blood cells are found in the dermis, which also play an important role in the immune system of the skin. Fibroblasts are directly related to aging because they have receptors for epidermal growth factor and fibroblast growth factor, and they generate collagen, elastin, and extracellular matrix.

This study involves the use of morin as a natural antioxidant to investigate its cytoprotective effects upon a UVA stimulus, which penetrates the dermal fibroblast layer and triggers cell reactions. Morin is a bioflavonoid that is abundant in fruit and vegetables. It shows various biological activities through cytoprotective, antimutation, and anti-inflammatory effects via antioxidative effects (Al-Numair et al. 2014), as an antioxidant that safely and biologically minimizes the damage due to free radicals (Zhang et al. 2009). This study confirms the antioxidant effects and cytoprotective effects of morin for the 
development of eco-friendly cosmetics and to provide baseline data for cosmeceutical research.

\section{Methods}

Cell culture and material treatment

Human dermal fibroblast cells (HDFs; Lonza, Switzerland) were incubated in Dulbecco's modified Eagle medium (DMEM; Hyclone, USA) with $10 \%$ fetal bovine serum (FBS; Hyclone), 1\% penicillin/streptomycin (penicillin $100 \mathrm{IU} / \mathrm{mL}$, streptomycin $100 \mu \mathrm{g} / \mathrm{mL}$; Invitrogen, USA) under conditions of $37{ }^{\circ} \mathrm{C}$, and $5 \% \mathrm{CO}_{2}$. The morin sample was purchased from Sigma Aldrich (USA) and 98\% purified. It was dissolved in dimethyl sulfoxide (DMSO; Sigma Aldrich) for the experiment. HDFs were incubated at a concentration of $1 \times 10^{6}$ cells/well for $24 \mathrm{~h}$, and the sample was pretreated in the medium for $6 \mathrm{~h}$. Afterward, the cells were stimulated with UVA. The sample was processed for $24 \mathrm{~h}$ to measure cell toxicity. The rest of the experiment, including the cell viability measurement, continued after $24 \mathrm{~h}$ of UVA irradiation via a UVA lamp (UVP, USA). The wavelength was measured with the Fiberoptic Spectrometer System USB2000 (Ocean Optics, USA). For UV irradiation, the medium was removed from the cell culture tray, which was subsequently cleaned twice with $\mathrm{pH}$ 7.4 phosphate-buffered saline (PBS). A total of $1 \mathrm{~mL}$ of PBS was poured into the cell culture tray to prevent the cells from drying. The lid was opened, and UVA irradiation was performed, after which PBS was removed from the tray and new medium was added for additional incubation for $24 \mathrm{~h}$.

\section{Cell viability}

The water-soluble tetrazolium salt-1 (WST-1) assay was used to test cell viability. Cells were introduced into a 96-well plate at a concentration of $3 \times 10^{3}$ cells/well in $100-\mu \mathrm{L}$ amounts and incubated for $24 \mathrm{~h}$. Morin was applied at varying concentration and additionally incubated for $24 \mathrm{~h}$. A total of $10 \mu \mathrm{L}$ of the EZ-Cytox cell viability assay kit reagent (ItsBio, South Korea) was added to the tray to measure the absorbance at $490 \mathrm{~nm}$ with a microplate reader (Bio-Rad, USA) after $1 \mathrm{~h}$. The experiment was repeated three times, from which the mean and standard deviation were calculated.

\section{mRNA expression}

The quantitative real-time polymerase chain reaction (qRT-PCR) was used to quantitatively analyze the gene expression associated with morin in HDF. In the PCR tube, $0.2 \mu \mathrm{M}$ primers, $50 \mathrm{mM} \mathrm{KCl}, 20 \mathrm{mM}$ Tris/ $\mathrm{HCl} \mathrm{pH}$ 8.4, $0.8 \mathrm{mM}$ dNTP, $0.5 \mathrm{U}$ Extaq DNA polymerase, $3 \mathrm{mM}$ $\mathrm{MgCl}_{2}$, and $1 \times \mathrm{SYBR}$ green (Invitrogen) were mixed to create the reaction solution. Linegene K (BioER, China) was used to perform PCR. Gene expression was measured using SYBR green, which binds to the extracted double-stranded mRNA. PCR was validated with a melting curve. The expression of each gene expression was normalized using the $\beta$-actin expression.

\section{Statistical analysis}

The statistical analyses were repeated three times for each independent experiment. The mean and standard deviation were calculated for each test result, for which statistical significance was analyzed by nonpaired Student's $t$ test.

\section{Results}

\section{Cytotoxicity of morin to HDFs}

WST-1 assay was performed to determine the toxicity of morin to cells. In the samples, the morin concentrations were set as $5,10,15,20$, and $50 \mu \mathrm{M}$. Cell viability was $108 \%$ at $10 \mu \mathrm{M}, 115 \%$ at $15 \mu \mathrm{M}, 122 \%$ at $20 \mu \mathrm{M}$, and $\geq$ $112 \%$ at $50 \mu \mathrm{M}$. Morin slightly decreased at $50 \mu \mathrm{M}$, but the cell viability rate was $\geq 100 \%$ (Fig. 1).

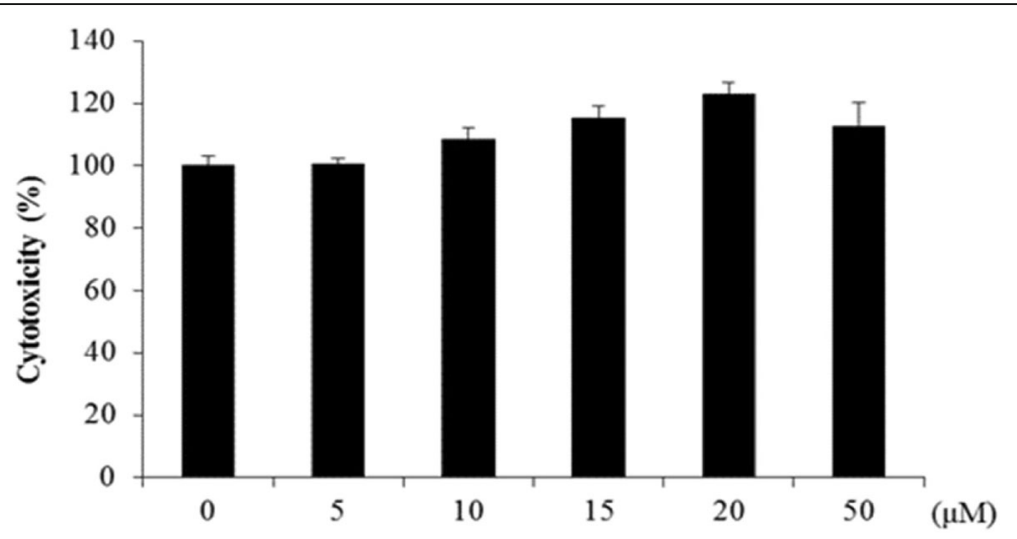

Fig. 1 Analysis of cytotoxic effects of morin on HDFs. Cells were inoculated in 96-well plates at a concentration of $3 \times 10^{3}$ cells/well and incubated for $24 \mathrm{~h}$. Morin was added to the wells and cultured for an additional $24 \mathrm{~h}$. Ten microliters of EZ-Cytox cell viability assay kit reagent (ItsBio, South Korea) was added to the incubated cell culture dish, and the absorbance was measured at $490 \mathrm{~nm}$ using a microplate reader (Bio-Rad, USA). The mean and standard deviation of cell viability were determined 
Effect of morin on the viability of UVA-irradiated HDFs HDFs were exposed to oxidative stress through UVA for the cell toxicity test. When the cells were irradiated with $10 \mathrm{~J} / \mathrm{cm}^{2}$ UVA, cell viability was reduced to $50.5 \%$. Consequently, the appropriate strength of UVA was set as $10 \mathrm{~J} / \mathrm{cm}^{2}$. After morin treatment, cell viability increased from $60.2 \%$ at $10 \mu \mathrm{M}$, to $91.8 \%$ at $20 \mu \mathrm{M}$, and to $102.8 \%$ at $50 \mu \mathrm{M}$. As $\geq 70 \%$ was considered high for cell viability, this study used 20 and $50 \mu \mathrm{M}$ morin samples simultaneously (Fig. 2).

\section{GPx1 mRNA expression}

Considering that glutathione peroxidase 1 (Gpx1) has a role in making ROS such as hydrogen peroxide and radicals less harmful or to convert them to water molecules with CAT, Gpx1 expression was calculated using qRT-PCR. In terms of the fold change of GPx1, it was shown that GPx1 mRNA was decreased to 0 . 83-fold through UVA irradiation, but increased to 1 . 01-fold at $20 \mu \mathrm{M}$ morin and 1.28-fold at $50 \mu \mathrm{M}$ morin (Fig. 3).

\section{CAT MRNA expression}

CAT removes toxins such as hydrogen peroxide and radicals to protect the cells. qRT-PCR was performed to measure CAT mRNA expression, which plays an important role in oxidoreduction reactions. In terms of the CAT mRNA fold change, there was a decrease to 0.65fold under UVA irradiation at $10 \mathrm{~J} / \mathrm{cm}^{2}$, but this was increased by morin to 0.98 -fold at $20 \mu \mathrm{M}$ and 1.28 -fold at $50 \mu \mathrm{M}$, showing an effect in a concentrationdependent manner (Fig. 4).

\section{HO-1 mRNA expression}

qRT-PCR was used to measure HO- 1 mRNA expression, which enables a rapid antioxidative mechanism through heme catabolism. In terms of the HO-1 mRNA fold change, there was an increase to 1.60 -fold through a sensitive reaction even before the sample treatment, and with morin, it was increased to 2.05 -fold at $20 \mu \mathrm{M}$ and 3.21-fold at $50 \mu \mathrm{M}$ (Fig. 5).

\section{NRF2 mRNA expression}

qRT-PCR was performed to measure the nuclear factor (erythroid-derived 2)-like 2 (NRF2) gene, which induces antioxidant enzyme expression. In terms of the NRF2 mRNA fold change, NRF2 mRNA decreased to 0.88 -fold and increased to 1.24-fold with $20 \mu \mathrm{M}$ morin and 1.56fold with $50 \mu \mathrm{M}$ morin under UVA irradiation (Fig. 6).

\section{Discussion}

In this study, UVA-induced cell activity and toxicity of morin were tested. As cell generation was thought to be higher when cell viability is $\geq 70 \%$, a high percentage > $100 \%$ may indicate an increase in physiological activity of HDFs and a lack of toxicity of morin. Therefore, it was verified that the concentration-dependent increase of catalase $(C A T)$ mRNA in morin induces the increase of CAT expression, a strong antioxidant enzyme that causes cell repair in response to cell damage and oxidization by UVA and inhibits or stabilizes hydrogen peroxide generation to inhibit lipid peroxide and protect cells. Through cytoprotective defense mechanisms, heme oxygenase-1 (HO-1) responds to oxidant stressors such as biliverdin, $\mathrm{CO}$, and free iron by inducing enzymes. Therefore, it has anti-inflammatory, antiapoptotic, and antiproliferative effects (Pae et al. 2004). This is because

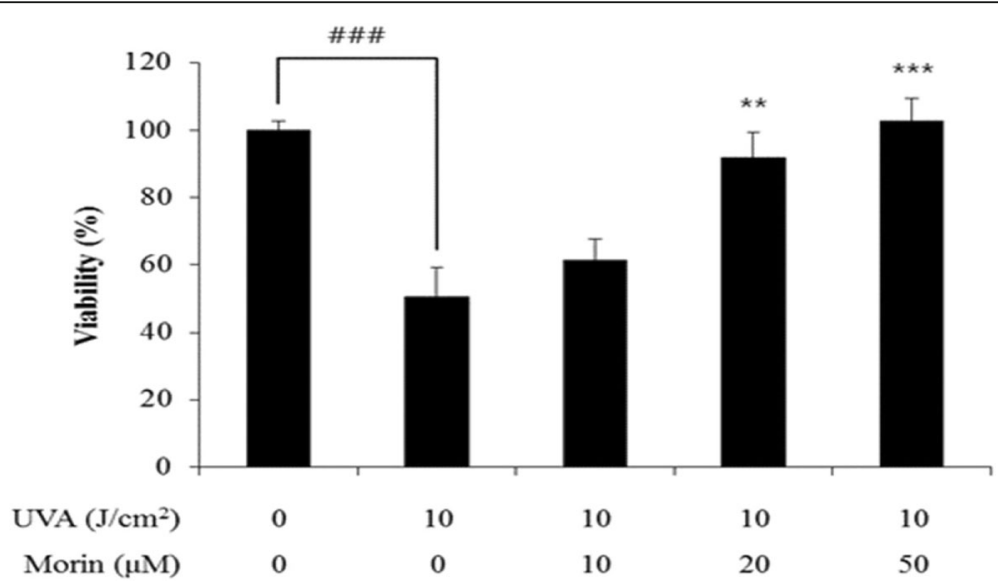

Fig. 2 The effect of morin on cell viability in UVA-irradiated HDFs. HDFs were cultured at $1 \times 106$ cells/well for 24 h, and then the sample was added to the culture medium and pretreated for $6 \mathrm{~h}$, followed by stimulation with UVA. In the cytotoxicity assay of morin, the cytotoxicity of the sample after treatment for $24 \mathrm{~h}$ was confirmed. After the UVA stimulation, $24 \mathrm{~h}$ after UVA irradiation, the cell viability and other experiments were performed. The data are expressed as means \pm SD (standard deviation) of the relative cell viability in each sample from triplicate experiments. Significantly different from control $\left.(\# \#)<0.001,{ }^{* *} p<0.01,{ }^{* * *} p<0.001\right)$ 


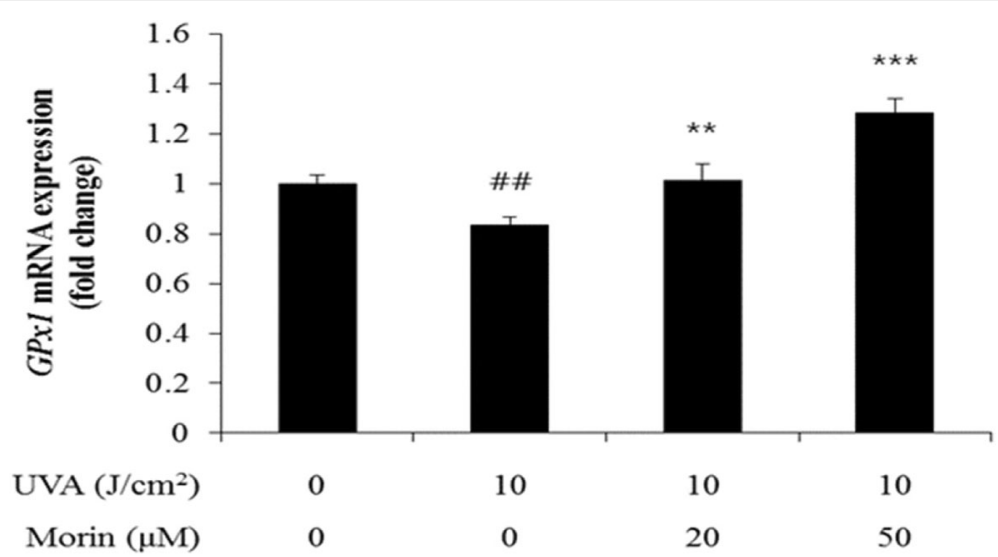

Fig. 3 The effect of morin on GPx1 expression in UVA-irradiated HDFs. Quantitative real-time polymerase chain reaction (qRT-PCR) was used to quantitatively analyze gene expression associated with morin in HDFs. qRT-PCR is a method for quantitatively measuring the level of DNA and the degree of activity of a specific gene. The amount of gene expression was measured using SYBR green in the double strand of extracted mRNA, and the validity of the PCR was confirmed by a melting curve. HDFs $(2 \times 105)$ were seeded in a 60-mm culture dish and incubated for $24 \mathrm{~h}$. Prior to UVA exposure, the cells were pretreated with various concentrations of morin. Then, the cells were washed with PBS and irradiated by $10 \mathrm{~J} / \mathrm{cm} 2$ UVA. After further incubation for $24 \mathrm{~h}$, the expression level of GPX1 mRNA was measured by qRT-PCR. The data are expressed as mean \pm SD of the relative cell viability in each sample from triplicate experiments $\left({ }^{\# \#} p<0.01,{ }^{* *} p<0.01,{ }^{* * *} p<0.001\right)$

the $\mathrm{HO}-1$ promoter induces $\mathrm{HO}-1$ through immediate early gene activation in the activator protein 1 (AP-1 site and degrades the pro-oxidant heme into antioxidant molecules to improve oxidative mechanisms) (Nimura et al. 1996; Wu et al. 1993). Therefore, the concentrationdependent increase of HO-1 mRNA in response to morin causes an increase in the expression of HO-1, which is a powerful antioxidant enzyme. As a result, polymers can be quickly converted to small molecules and ATP (adenosine triphosphate energy) through heme catabolism in order to protect the cells from damage and oxidation due to ultraviolet rays. As HO-1 increased compared with that before the sample treatment, it was confirmed that $H O-1$ acted as a natural defense mechanism against oxidative stress by UVA. Along with $\mathrm{HO}$ $1, N R F 2$ is a powerful protein induced by Keap1 to activate antioxidative mechanism through its assistance in antioxidant gene expression, and it usually stays dormant in cells (Ishii et al. 2000). NRF2 is a transcription factor induced by ARE to play an essential role in gene expression for detoxification and oxidative stress. Therefore, the concentration-dependent increase of $N R F 2$ mRNA verifies that morin increases the expression of $N R F 2$, a powerful antioxidant enzyme, to protect cells through its assistance in antioxidant enzyme gene expression against cell damage and oxidization.

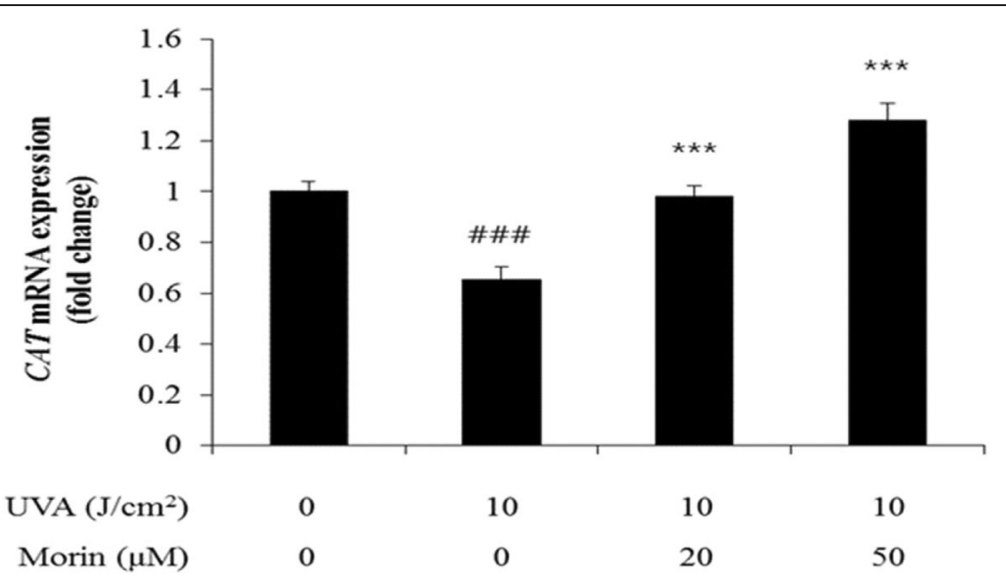

Fig. 4 The effect of morin on CAT mRNA expression in UVA-irradiated HDFs. HDFs $(2 \times 105)$ were seeded in a 60-mm culture dish and incubated for 2-4 h. Prior to UVA treatment, cells were pretreated with various concentrations of morin. Then, cells were washed with PBS and irradiated by $10 \mathrm{~J} / \mathrm{cm} 2$ UVA. After further incubation for $24 \mathrm{~h}$, the expression level of CAT mRNA was measured by qRT-PCR. The data are expressed as mean \pm

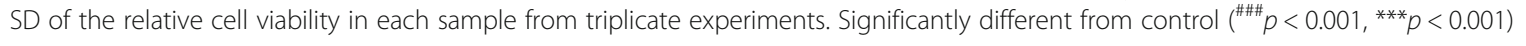




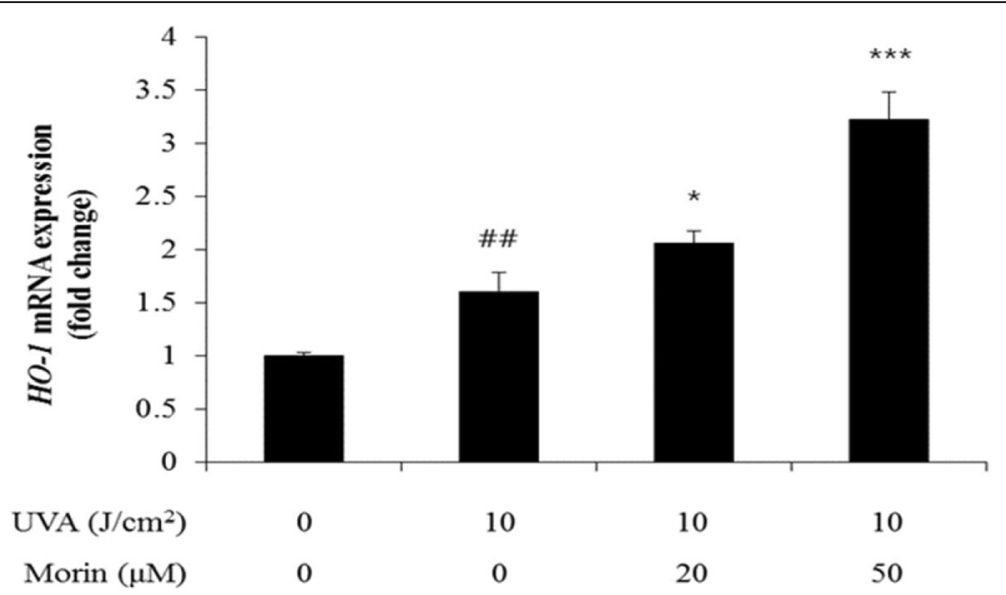

Fig. 5 The effect of morin on the expression of HO-1 mRNA in UVA-irradiated HDFs. HDFs $(2 \times 105)$ were seeded in a 60-mm culture dish and incubated for $24 \mathrm{~h}$. Prior to UVA treatment, cells were pretreated with various concentrations of morin. Then, cells were washed with PBS and irradiated with-10 J/cm2 UVA. After further incubation for $24 \mathrm{~h}$, the expression level of HO-1 mRNA was measured by qRT-PCR. The data are expressed as mean \pm SD of the relative cell viability in each sample from triplicate experiments. Significantly different from control $(\# \#<0.01$, $\left.{ }^{*} p<0.5,{ }^{* * *} p<0.001\right)$

\section{Conclusions}

This study confirmed the applicability of the flavonoid morin as an eco-friendly antioxidative cosmetic ingredient for skin cytoprotective and antioxidant effects against UVA-induced free radicals. This experiment focused on HDFs, which penetrate down into the dermal layer and enable cytoprotection. UVA was selected as a stimulant to test the antioxidant effect and antioxidant enzyme gene expression of morin. In conclusion, the experiment on the UVA-induced antioxidant effect of morin through GPx1, CAT, HO-1, and NRF2 gene expression under stimulation with $1 \mathrm{~J} / \mathrm{cm}^{2}$ UVA showed that the expression of GPx1, CAT, HO-1, and NRF2 was increased in a morin concentration-dependent manner.
GPx1 expression increased as a catalyst that converts hydrogen peroxide and free radicals from ROS into less harmful molecules, or water through oxidoreduction reactions, along with $C A T$. Therefore, this study confirmed that GPX1 and CAT protect proteins and eliminate oxidants through a primary cytoprotective effect against acute oxidative stress. HO-1 increased under UVA irradiation, presumably through sudden induction of antioxidant mechanisms by converting polymers to small molecules and ATP through heme catabolism. In addition, HO-1, which promotes the expression of antioxidant enzymes through immediate early gene activation in response to ultraviolet light, is induced by NRF2, a powerful protein that enables antioxidant mechanisms.

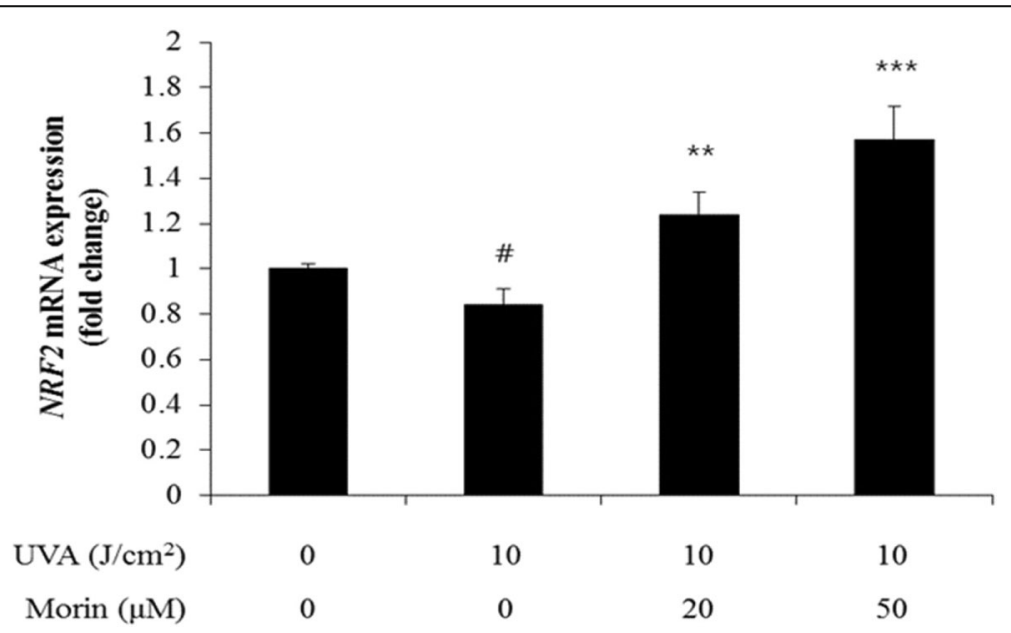

Fig. 6 The effect of morin on the expression of NRF-2 mRNA in UVA-irradiated HDFs. HDFs $(2 \times 105)$ were seeded in a 60-mm culture dish and incubated for $24 \mathrm{~h}$. Prior to UVA treatment, cells were pretreated with various concentrations of Morin. Then, cells were washed with PBS and irradiated by $10 \mathrm{~J} / \mathrm{cm} 2$ UVA. After further incubation for $24 \mathrm{~h}$, the expression level of NRF2 mRNA was measured by qRT-PCR. The data are expressed as mean \pm SD of the relative cell viability in each sample from triplicate experiments. Significantly different from control $\left({ }^{*} p<0.5,{ }^{* *} p<0.01,{ }^{* * *} p<0.001\right)$ 
NRF2 is decomposed by oxidative stress from its form in the combined antioxidant network of NRF2-KEAP1 to adjust the expression of various antioxidant factors. Consequently, morin increased HO- 1 and NRF2 gene expression in a concentration-dependent manner, to enable an oxidoreduction mechanism through photoaging. In summary, morin has been proven to have an antioxidative effect to maintain cellular homeostasis and protect cells through blocking or delaying cell transformation. To conclude, this study verified the applicability of morin as a cosmetic ingredient that protects cells by increasing cytoprotective gene expression, in a concentration-dependent manner. These genes respond to oxidative stress from UVA exposure to remove ROS, a natural by-product of oxygen metabolism, and protect neurons from toxicity. These findings suggest a major role of morin in cell signaling and homeostasis as an applicable cosmetics ingredient.

\section{Abbreviations}

AP-1: Activator protein 1; ARE: Antioxidant response element; ATP: Adenosine triphosphate; DNA: Deoxyribonucleic acid; KEAP1: Kelch-like ECH-associated protein 1; Maf: Musculoaponeurotic fibrosarcoma; mRNA: Messenger RNA or messenger ribonucleic acid; NRF2: Nuclear factor (erythroid-derived 2)-like 2; ROS: Reactive oxygen species; UV: Ultraviolet ray; UVA: Ultraviolet absorption

\section{Acknowledgements}

Not applicable

Funding

Not applicable

Availability of data and materials

Not applicable

Authors' contributions

HJY and JJA conceived and wrote the editorial. Both authors read and approved the final manuscript.

Ethics approval and consent to participate

Not applicable

\section{Consent for publication}

Not applicable

\section{Competing interests}

The authors of this editorial article are members of the Editorial Board of Biomedical Dermatology. Both authors declare that they have no competing interests.

\section{Publisher's Note}

Springer Nature remains neutral with regard to jurisdictional claims in published maps and institutional affiliations.

\section{Author details}

'Beauty People Beauty School, 68 Dolma-ro, Bundang-gu, Seongnam-si 13627, Gyeonggi-do, Republic of Korea. ${ }^{2}$ Department of Cosmetology, Suwon Women's University, Suwon-si, Kyonggi-do, South Korea.
Received: 18 September 2017 Accepted: 14 March 2018

Published online: 15 April 2018

\section{References}

Al-Numair KS, Chandramohan G, Alsaif MA, Veeramani C, El-Newehy AS. Morin, a flavonoid, on lipid peroxidation and antioxidant status in experimental myocardial ischemic rats. Afr J Tradit Complement Altern Med. 2014;11(3):14-20.

Bhattacharya IS, Woolf DK, Hughes RJ, Shah N, Harrison M, Ostler PJ, Hoskin PJ. Stereotactic body radiotherapy (SBRT) in the management of extracranial oligometastatic (OM) disease. Br J Radiol. 2015;88(1048):1-5.

Cabiscol E, Tamarit J, Ros J. Oxidative stress in bacteria and protein damage by reactive oxygen species. Int Microbiol. 2000;3(1):3-8,

Canning P, Sorrell FJ, Bullock AN. Structural basis of Keap1 interactions with NRF2. Free Radic Biol Med. 2015;88:101-7.

Castro L, Freeman BA. Reactive oxygen species in human health and disease. Nutrition. 2001;17(2):623-6.

Ichihashi M, Ando H, Yoshida M, Niki Y, Matsui M. Photoaging of the skin. AntiAging Medicine. 2009;6(6):45-59.

Ishii T, Itoh K, Takahashi S, Sato H, Yanagawa T, Katoh Y, Bannai S, Yamamoto M. Transcription factor NRF2 coordinately regulates a group of oxidative stressinducible genes in macrophages. J Biol Chem. 2000;275(21):16023-9.

Kansanen E, Kuosmanen SM, Leinonen H, Levonen AL. The Keap1-NRF2 pathway: mechanisms of activation and dysregulation in cancer. Redox Biol. 2013;1(1): 45-9.

Matés JM. Effects of antioxidant enzymes in the molecular control of reactive oxygen species toxicology. Toxicology. 2000;16(153):83-104.

Mates JM, Segura JA, Alonso FJ, Marquez J. Central role of heme oxygenase-1 in cardiovascular protection. Aioxidants \& Redox Signaling. 2012;15(7):35-1846.

Nimura T, Weinstein PR, Massa SM, Panter S, Sharp FR. Heme oxygenase-1 (HO-1) protein induction in rat brain following focal ischemia. Mol Brain Res. 1996; 37(1):201-8.

Pae HO, Oh GS, Choi BM, Chae SC, Kim YM, Chung KR, Chung H. Carbon monoxide produced by heme oxygenase-1 suppresses T cell proliferation via inhibition of IL-2 production. The Journal of Immunulogy. 2004;172(8):4744-51.

Wu TW, Zeng LH, Wu J, Fung KP. Morin hydrate is a plant-derived and antioxidant-based hepatoprotector. Life Sci. 1993;53(13):213-8.

Zhang R, Kang KA, Piao MJ, Maeng YH, Lee KH, Chang WY, You HJ, Kim JS, Kang SS, Hyun JW. Cellular protection of morin against the oxidative stress induced by hydrogen peroxide. Chemico-Interactions. 2009;177(1):21-7.
Submit your next manuscript to BioMed Central and we will help you at every step:

- We accept pre-submission inquiries

- Our selector tool helps you to find the most relevant journal

- We provide round the clock customer support

- Convenient online submission

- Thorough peer review

- Inclusion in PubMed and all major indexing services

- Maximum visibility for your research

Submit your manuscript at www.biomedcentral.com/submit
Ciomed Central 